\title{
COMUNICAÇÃO
}

\section{TRABALHO REGULAR PARA OS HOMENS E PRECÁRIO PARAAS MULHERES NAPRODUÇÃO DE FRUTAS}

\author{
Regular work for men and precarious work for women in the fruits production
}

\author{
Dalva Maria da Mota ${ }^{1}$
}

\begin{abstract}
RESUMO
Objetivou-se com o artigo analisar as particularidades da geração de ocupações para homens e mulheres no projeto empresarial de irrigação Platô de Neópolis, localizado no Baixo São Francisco Sergipano. Com as principais conclusões, verifica-se que a política de irrigação influenciou substancialmente na reestruturação do mercado de trabalho local, apesar da desproporcionalidade entre o número de empregos previstos e gerados, com a predominância da contratação registrada de homens jovens e a quase exclusão das mulheres das ocupações assalariadas na agricultura moderna.
\end{abstract}

Termos para indexação: Fruticultura Irrigada, Trabalho de Homens, Trabalho de Mulheres, Gênero, Platô de Neópolis.

\begin{abstract}
The aim of this article is to analyse the peculiarities of job generation for men and women of the Platô de Neópolis Irrigation Business Project, located in the Lower São Francisco region of Sergipe The main conclusion is that the irrigation policy substantially influenced the restructuring of the local labour market, in spite of the disparity between the number of jobs predicted and generated, with the predominance of registered work contracts going to young men and the almost complete exclusion of women from salaried occupations in modern agriculture.
\end{abstract}

Index terms: Fruitculture, Men's Work, Work's Women's Work, Gender.

(Recebido para publicação em $1^{\circ}$ de outubro de 2003 e aprovado em 16 de junho de 2004)

\section{INTRODUÇÃO}

Em visita realizada ao Projeto de Irrigação Platô de Neópolis em 1998, um fato chamou a atenção: a predominância de trabalhadores homens migrantes que assalariavam-se temporariamente, mesmo para aquelas atividades consideradas "leves" e que predominavam no projeto sobre a população local, ainda que os empregadores assumissem custos adicionais (alojamento e transporte) para viabilizar a participação desses trabalhadores nos processos produtivos.

Em pesquisa seqüenciada no período de 1998/2002², constatou-se uma retração dos migrantes e uma valorização dos trabalhadores de origem local e pertencentes a redes de interconhecimento que mesclavam relações de parentesco, vizinhança e camaradagem. Apesar das mudanças verificadas, uma continuidade se evidenciava: a quase exclusão das mulheres das atividades de produção de frutas tropicais irrigadas, apesar da constatação de que no passado

${ }^{2}$ Como parte de uma pesquisa mais ampla sobre trabalho e sociabilidade na fruticultura irrigada realizada para elaboração de uma tese de doutorado da autora na Universidade Federal de Pernambuco no período 1999/2002. recente - até os anos 90 - as mulheres trabalhavam no âmbito da família na agricultura familiar e na cana-de-açúcar como assalariadas.

O trabalho na agricultura brasileira é um fenômeno que tem sido abordado na literatura pelo estudo do colonato do café, dos bóias-frias da cana-de-açúcar, dos trabalhadores da borracha (STOLCKE, 1982). Mais recentemente, sob a ótica do gênero, foi objeto de atenção no Vale do São Francisco (CAVALCANTI, 1999) e em outros países da América Latina, como o México (LARA, 1998), a Argentina (BENDINI, 1999) e o Uruguai. Em que pese o reconhecimento da ampliação da participação das mulheres no mercado de trabalho e na agricultura, em particular, no Platô de Neópolis, evidenciase uma tendência inversa: a quase exclusão das mulheres do assalariamento na agricultura. Esse fenômeno, dada a sua particularidade, não tem sido destacado nas pesquisas em decorrência do reconhecimento mundial de que elas ampliaram a sua participação no mercado de trabalho, muito embora as desigualdades e a precariedade seja uma constatação na pauta de análise de muitos estudiosos (HIRATA, 1998). 
Abre-se, assim, mais um campo de análise: o do mercado de trabalho agrícola, que incorpora homens e rejeita mulheres, sob os argumentos da força física, muito embora haja o reconhecimento de que as mulheres são portadoras de habilidades e qualificações muito úteis na produção de frutas para consumidores exigentes e situados, muitas vezes, nos países do norte.

Nesse contexto, objetivou-se com o artigo analisar as particularidades da geração de ocupações para homens e mulheres no projeto empresarial de irrigação Platô de Neópolis, localizado no Baixo São Francisco Sergipano.

\section{ÁREADEPESQUISA}

O Projeto de Irrigação Platô de Neópolis ${ }^{3}$ foi implantado no início dos anos 90 do Século XX, em terras antes cultivadas com cana-de-açúcar, pecuária e culturas alimentares. Ocupa parte dos municípios de Neópolis, Japoatã, Pacatuba e Santana do São Francisco e sua implantação é parte de uma estratégia de estabelecimento de pólos de desenvolvimento para minimizar os efeitos das políticas de geração de energia ${ }^{4}$ sobre as populações locais. Foi também inspirado nas experiências nordestinas de produção de frutas frescas, economicamente bemsucedidas e pautadas na forte intervenção estatal, cujos exemplos mais característicos são o Vale do São Francisco, em Pernambuco e Bahia (CAVALCANTI, 1997, 1999; SILVA, 1999) e o Vale do Açu e Mossoró, no Rio Grande do Norte (SILVA, 1999).

É resultado de uma intervenção inovadora do Estado para o estabelecimento de "ilhas" de modernização, via empreendimentos empresariais, sustentados no trabalho assalariado e em altos níveis tecnológicos, com possibilidade de vinculação aos mercados nacional e

\footnotetext{
${ }^{3}$ Tem a denominação "Platô de Neópolis" devido a sua constituição geomorfológica apresentar um relevo quase plano, circundado por encostas, constituindo-se parte dos tabuleiros costeiros de Sergipe.

${ }^{4}$ Através da construção da barragem Xingó no Baixo São Francisco Sergipano.

${ }^{5}$ Os sistemas de produção são: coco, banana, manga, citros, diversificado sem coco e diversificado com coco.

${ }^{6}$ Apesar de ocupar área tão expressiva, a cultura do coqueiro é que menos demanda mão-de-obra no sistema irrigado.

${ }^{7}$ Caracterizados por sua alta eficiência na aplicação de água, de forma localizada, na região das raízes, com economia de energia, por necessitarem de baixa pressão. Esses sistemas permitem diversos graus de automação, inclusive automação total, além de permitir aplicações de fertilizantes via água, a fertirrigação, melhorando a disponibilidade de nutrientes para as culturas irrigadas.
}

internacional. Diferentemente de todos os projetos nordestinos, tem um modelo que apresenta, desde o início, a parceria entre o Estado, por meio da Secretaria da Agricultura de Sergipe, e a iniciativa privada. Coube ao Estado, o planejamento e a instalação da infra-estrutura de irrigação fora dos lotes, e aos empresários, os investimentos nas parcelas, a implementação da produção e da comercialização mediante um condomínio denominado Associação dos Concessionários do Projeto Platô de Neópolis- ASCONDIR.

O projeto é formado por 38 lotes, cujos tamanhos variam de 20 a 600 hectares. Até dezembro de 2001, 60\% da área do projeto estavam ocupados com 06 sistemas de produção frutícolas ${ }^{5}$. A cultura do coqueiro ${ }^{6}$ ocupava $31 \%$ da área plantada, cultivada em vinte dos trinta e oito lotes, e o sistema de monocultura encontra-se em seis empresas. Todas as empresas têm em comum sistemas de irrigação automatizados de alta tecnologia, como microaspersão e gotejamento com utilização de fertirrigação ${ }^{7}$. No entanto, a condução dos itinerários técnicos diferem, a depender do estágio de cultivo, da área plantada, da disponibilidade de capital, do nível técnico dos gerentes e da estratégia interna adotada para a produção e comercialização.

\section{METODOLOGIA DEPESQUISA}

Os dados analisados neste artigo foram levantados no Projeto Empresarial de irrigação Platô de Neópolis, localizado no Baixo São Francisco Sergipano. Foram levantados em pesquisa documental-censitária e empírica realizada em quatro fases. A primeira, no período de dezembro/97 a abril/98, com a totalidade dos administradores dos 21 lotes em funcionamento do projeto, foi feita mediante aplicação de questionários com perguntas fechadas e abertas sobre: sistemas de produção em uso, número de trabalhadores permanentes e temporários, tipos de ocupação, níveis de escolaridade e salários (MOTA, 1999). A segunda etapa, entre janeiro e março/2000, constou de entrevistas com 17 atores-chave (líderes sindicais, trabalhadores permanentes e temporários) e objetivou levantar e compreender as representações dos diferentes atores sobre as suas inserções no projeto. A terceira etapa ocorreu por meio de observações dos processos de trabalho e da aplicação de questionários para $100 \%$ dos trabalhadores de sete lotes, exclusivamente plantados com banana (02 lotes) e coco (05 lotes), onde podiam ser observadas todas as etapas de produção. O conteúdo de pesquisa constou de dados para a construção dos perfis dos trabalhadores (características

Ciênc. agrotec., Lavras, v. 29, n. 4, p. 899-906, jul./ago., 2005 
individuais e familiares, trajetórias profissionais).A quarta e última etapa ocorreu em agosto de 2003 e constou de visita a todos os lotes para levantamento do número de empregos gerados, assim com da sua associação com ocupações de homens e mulheres por sistema de produção. Nessa etapa foram realizadas histórias de vida com as mulheres e a elaboração de suas histórias de trabalho privilegiando os seguintes temas: origem, ocupação dos pais, iniciação ao trabalho, qualificações formais, ingresso no trabalho agrícola, papel da família na iniciação ao trabalho, períodos de emprego e desemprego, dentre outros temas.

\section{HOMENSEMULHERES NAPRODUÇÃODE FRUTAS}

\section{Perfis dos trabalhadores}

Os dados relativos ao perfil dos trabalhadores demonstram que a maioria deles é natural de municípios circunvizinhos ao Platô (47\%) ou de outros municípios do Estado de Sergipe (22\%), sendo os demais provenientes do Estado de Alagoas (25\%) e de outros Estados da região Nordeste (6\%).

Do total dos trabalhadores que não nasceram nos municípios circunvizinhos ao Projeto, 31,1\% afirmaram que mudaram de residência para aí trabalhar, o que demonstra que, não obstante o funcionamento ainda parcial do projeto, o Platô já se configura como um pólo de atração de trabalhadores em um momento em que outros investimentos agrícolas liberam mão-de-obra. A mudança de local de residência está associada também às relações preexistentes na região onde se localiza o Platô de Neópolis (parentes residindo na região) e a faixa de idade dos trabalhadores que são predominantemente jovens $(76 \%$ têm até 30 anos) e têm mais facilidade para transitarem em busca de melhores oportunidades de trabalho pelo fato de não terem famílias numerosas para sustentar.

A composição de uma força de trabalho tão jovem tem como princípio básico o aproveitamento do vigor físico, considerando que $63 \%$ da amostra total são de trabalhadores rurais, ocupação em que a força e capacidade físicas são pré-requisitos indispensáveis, utilizados também como meio de exclusão das mulheres, que correspondem a apenas $1,6 \%$ do total da amostra, assim mesmo em atividades burocráticas e de limpeza de escritórios.
Quanto ao estado civil dos trabalhadores, 57\% são casados, $38 \%$ são solteiros e os demais são separados. Dos trabalhadores casados, $65 \%$ têm filhos e as famílias não são numerosas, considerando que $56 \%$ têm até dois filhos, $19 \%$ têm de três a quatro e os demais não têm filhos. Observando os dados relativos ao padrão de reprodução social das famílias a que esses trabalhadores pertencem, o número médio de filhos eram 6 e esse padrão tende a baixar para os descendentes, no caso, os trabalhadores do Platô.

Os lugares de residência de $49 \%$ dessas famílias são os povoados circunvizinhos ao projeto (Tatu, Novo Horizonte, Mundéu da Onça e Saúde), enquanto 38\% se distribuem entre uma das cinco sedes municipais próximas ao Platô (Penedo, Neópolis, Japoatã, Santana do São Francisco, Pacatuba). Os demais habitam em povoados mais distantes da região.

Viver em um dos povoados circunvizinhos ao projeto é mais barato, tanto pela facilidade de acesso às residências, quanto ao fato de poder utilizar bicicletas para se deslocar, o que evita custos adicionais com transporte. É também importante a permanência nas comunidades onde nasceram e cresceram, com a manutenção dos convívios com parentes e vizinhos, tão importantes na sociabilidade das populações rurais.

O grau de escolaridade dos trabalhadores é muito baixo: $42 \%$ assinam o nome, $42 \%$ cursaram até a $4^{\mathrm{a}}$ série, $14 \%$ têm o 2 o grau e os demais cursaram a universidade.

Apesar das inserções profissionais dos trabalhadores em atividades que utilizam tecnologia de ponta, seus índices de escolaridade não diferem dos índices dos outros trabalhadores da Região Nordeste, cujo porcentual de analfabetos é de $42 \%$ da população. O baixo índice de escolarização não impede que os trabalhadores realizem atividades que utilizam tecnologia de ponta, após rápidos treinamentos em serviço.

\section{Sistemas de produção versus ocupações}

Quanto aos sistemas de produção, predominam aqueles de culturas perenes. O coco, os citros, a banana, a manga, dentre outras culturas, têm conquistado importantes janelas do mercado nacional. São cultivados com o uso intensivo de tecnologia e com um mínimo de trabalho humano, conforme demonstra o quadro seguinte: 
QUADRO 1 - Sistemas de produção, área implantada e nº de trabalhadores - 2001.

\begin{tabular}{|c|c|c|c|c|c|c|c|}
\hline \multirow{3}{*}{ Sistema de Produção } & \multirow{3}{*}{$\begin{array}{c}\text { Área } \\
\text { Implantada } \\
\text { (ha) }\end{array}$} & \multicolumn{5}{|c|}{ Número de Trabalhadores } & \multirow{3}{*}{$\begin{array}{c}\text { Número } \\
\text { ha/h }\end{array}$} \\
\hline & & \multicolumn{2}{|c|}{ Registrados } & \multicolumn{2}{|c|}{ Clandestinos } & \multirow{2}{*}{ Total } & \\
\hline & & Homens & Mulheres & Homens & Mulheres & & \\
\hline Coco & 754 & 91 & - & 39 & - & 130 & 5.8 \\
\hline Banana & 164.23 & 51 & - & 1 & - & 52 & 3.1 \\
\hline Manga & 58 & 6 & 4 & 1 & 1 & 12 & 4.8 \\
\hline Citros & 559 & 58 & 1 & 15 & - & 74 & 7.5 \\
\hline $\begin{array}{l}\text { Diversificado sem } \\
\text { coco }\end{array}$ & 1.149 .2 & $198 \square$ & $14 \square$ & 45 & 25 & 282 & 4.0 \\
\hline $\begin{array}{l}\text { Diversificado com } \\
\text { coco }\end{array}$ & 1.583 & 208 & 9 & 71 & 9 & 297 & 5.3 \\
\hline TOTAL & 4267.43 & 612 & 28 & 172 & 35 & 847 & 5.0 \\
\hline
\end{tabular}

Fonte: Pesquisa realizada pela autora em junho de 2001.

A principal cultura em termos de geração de ocupação é a banana, com 3,1 hectare/trabalhador em decorrência dos trabalhos de pós-colheita, que ocupam 4,7 trabalhadores por mês. Não se registra para esse cultivo o emprego das mulheres, em virtude de os empregadores considerarem que são atividades que demandam força física, qualidade "naturalmente" atribuída aos homens. Em se tratando de atribuições "naturais", as mulheres estão reconhecidas como excelentes polinizadoras de maracujá. No entanto, essa cultura está concentrada em apenas três empresas e ocupando menos de $1 \%$ da área irrigada do Platô.

As culturas que ocupam maiores áreas são os citros (laranja, limão, tangerina, lima-da-pérsia) e o coco, respectivamente com $42 \%$ e $31 \%$ da área cultivada. A quantidade de ocupações na produção de citros é de 7,5 hectares para cada trabalhador, menor índice de ocupação entre as culturas do Platô, tendendo a empregar mais quando todos os pomares estiverem em plena produção. Para a produção de coco, o número de ocupações geradas tem sido de 5,8 hectares para cada trabalhador. É uma cultura que ocupa exclusivamente homens e já se encontra em plena produção. Em ambos os casos, as ocupações têm sido predominantemente registradas (MOTA, 1999).
A cultura da manga é a terceira em termos de geração de ocupação. Tem altos custos de implantação e se adequa muito bem aos serviços mecanizados e os maiores requisitos de trabalho concentram-se nas etapas de irrigação e colheita. No entanto, em face das exigências externas de menor manuseio das frutas frescas, é provável que, rapidamente, essa atividade seja automatizada.

Comparando a geração de empregos no Platô de Neópolis com o Vale do São Francisco, constatam-se algumas diferenças importantes. No Vale, a cultura da manga é a que tem maior área plantada e ocupa um homem para cada dois hectares (CAVALCANTI e IRMÃO, 1994) enquanto no Platô essa mesma relação foi de um homem para cada 4,8 hectares (MOTA, 1999). A desproporcionalidade entre o número de pessoas ocupadas, em cada caso deve-se ao fato de que no Vale do São Francisco os pomares já estão produzindo, e no Platô encontram-se em implantação ou com uma produção inicial bem abaixo da capacidade total, ainda não computados os números relativos à pós-colheita. Nas duas experiências, as atividades são desenvolvidas, produtores a utilização de mão-de-obra temporária para atender às necessidades de trabalho de determinadas fases, como por exemplo: poda, raleio e colheita" (CAVALCANTI e IRMÃO, 1994, p. 67). 
No Platô, a cultura líder em termos de geração de ocupação é a banana, que para cada 3,1 hectares, ocupa um trabalhador. Esse número é decorrente de ser uma cultura que tem trabalho de pós-colheita para ser comercializada. Para todas as culturas, os números revelam uma tendência de menor utilização do trabalho no Platô de Neópolis, em decorrência de as culturas que ocupam maior área (citros e coco) não dependerem de serviços intensos de pós-colheita. Outro aspecto é que são sistemas que utilizam exclusivamente trabalho assalariado e, como tal, remanejam a força-de-trabalho da forma que seja conveniente para diminuir custos de produção.

Comparando o número de ocupações geradas pela manga no Vale, com o Platô pode-se inferir uma tendência de ampliação do número de trabalhadores nesse último projeto, quando o sistema de produção estiver funcionando em todas as suas etapas. O número que se estima em termos de ampliação de trabalhadores é de 139. Essa mesma projeção para os citros é de 250 ocupações, mas considerando o número médio de ocupações para todas as culturas que é de 5 hectares por trabalhador. Ainda em se tratando de tendências, prevê-se, que se mantidos os coeficientes atuais, o Platô gerará um total de cerca de 1400 ocupações quando estiver em pleno funcionamento.

\section{Trabalho das mulheres: raro e precário}

Em pesquisa realizada no Platô, observou-se que as mulheres constituem apenas $1,6 \%$ do total dos trabalhadores, assim mesmo, mais da metade trabalha de forma temporária e clandestina (MOTA, 2001). Já no Vale do São Francisco, Cavalcanti $(1997,1999)$ constatou que as novas oportunidades de emprego contribuíram, principalmente, para a ampliação do mercado de trabalho

\footnotetext{
${ }^{8}$ As mulheres têm se estabelecido no Vale do São Francisco como especialistas em atividades consideradas "leves" no cultivo da uva. Nem por isso, no entanto, têm estabilidade em decorrênica das seguidas exigências dos importadores que querem, cada vez mais, produtos com menos trabalho manual (Cavalcanti \& Silva, 1998). Ao contrário, no Platô de Neópolis, só ocasionalmente, as mulheres são contratadas, assim mesmo, de forma precária. Influencia nesta diferenciação da inserção das mulheres os tipos de culturas e o padrão cultural predominantemente pesadas.

${ }^{9}$ Os entrevistados afirmam que um pequeno número de mulheres assalariavam-se na cana-de-açúcar, inclusive, para as mesmas atividades dos homens: o corte. No entanto, este assalariamento era também temporário e em épocas que o contingente masculino não supria a demanda. Há consenso entre homens e mulheres entrevistados que o desempenho das mesmas era compatível ao dos homens. $\mathrm{O}$ que, provavelmente, as discriminava nas contratações era a vulnerabilidade pelo fato de terem sempre dupla jornada de trabalho e serem mais susceptíveis aos problemas domésticos.
}

para as mulheres ${ }^{8}$, tendência observada por Lara (1998) no México e por Antunes (1999) para os diferentes setores da economia mundial, inclusive em áreas não tradicionalmente ocupadas por mulheres, como é o caso da indústria microeletrônica e do setor de serviços. No entanto, há a constatação de que o número de vagas vem sofrendo uma gradativa redução pela substituição do trabalho humano pela tecnologia, a exemplo da fertirrigação e da automatização da irrigação. As mulheres são as mais prejudicadas, seja pela maior peso dos encargos trabalhistas, seja pelo fato de acumularem dupla jornada e serem responsáveis diretas pelos filhos, conseqüentemente, mais susceptíveis aos acontecimentos externos ao trabalho; ou ainda, pela noção usualmente compartilhada por homens e mulheres, trabalhadores da agricultura, de que a mulher só é capaz de executar tarefas leves e delicadas, o que escamoteia a qualificação obtida no dia-a-dia do trabalho. Nesse particular, as mulheres argumentam que as atividades na produção de coco, por exemplo, não é adequada para elas, em decorrência da força física que demanda.

Todas essas assertivas são válidas para o contexto do Platô, mas existem ainda outras razões que têm impedido uma incorporação mais constante das mulheres no trabalho assalariado. Segundo as informações coletadas nas entrevistas, na região, as atividades das mulheres, ainda estão muito associada à ajuda e, como tal, não têm registro em sistemas de produção, cuja lógica é estritamente empresarial.

A literatura registra que em períodos anteriores à implantação do Platô, o acesso a terra para agricultura estava muito limitado, assim mesmo, na condição de morada ou arrendamento nas fazendas ou nas propriedades rizicultoras. A fragilidade das unidades agrícolas de produção dessa região teve como conseqüência a pluralidade de atividades, entre as quais, o assalariamento de algumas poucas mulheres na cana-de-açúcar ${ }^{9}$, assim mesmo, no curto tempo de funcionamento da Usina Grande Vale. Esse número reduzido de mulheres assalariadas é decorrente da concepção de que aquele era um tipo de ambiente pouco propício às mulheres casadas. Esse ambiente tornou-se suspeito, pelas insinuações de relações amorosas, principalmente entre recrutadores da força-detrabalho e trabalhadoras. Aliás, esse é um fato observado e analisado em outras regiões do Brasil, a exemplo do estudo de Stolcke (1982) sobre sistemas de trabalho e estrutura familiar nas fazendas de café em São Paulo. "As turmas de trabalhadores são geralmente vistas como 
lugares de moral duvidosa, impróprias para mulheres respeitáveis. Os turmeiros têm a fama, que não é infundada, de tirar proveito de sua posição para seduzir as trabalhadoras" (STOLCKE, 1982, p. 76). Assim sendo, na região do Platô, as atividades assalariadas na agricultura eram, particularmente, desenvolvidas pelas mulheres solteiras e limitada à adubação, situação possível de ser observada também na atual agricultura irrigada.

As experiências que essas mulheres acumulam como trabalhadoras na agricultura familiar não têm distintivos positivos, quando comparadas com as dos homens. Por serem atividades controladas pelos homens, têm um sentido de ajuda e não de obtenção da renda central na reprodução da família, condição que ainda está associada aos homens. A única exceção é a adubação manual, considerada uma atividade leve e sem grandes exigências por homens e mulheres. Aliás, essa atividade, intensa na fase de formação de pomares, tende a diminuir pela substituição pela fertirrigação. Por outro lado, em nenhuma das principais culturas implantadas no Platô (coco, laranja, tangerina), as mulheres têm um papel exclusivo. Ao contrário, na agricultura familiar ou empresarial local, a cultura do coco está intimamente associada aos homens, também na perspectiva de gênero, principalmente pelo reconhecimento de que a colheita dos frutos depende de habilidades atribuídas aos homens para escalar os coqueiros, muito embora as árvores do Platô sejam baixas e a colheita dependa de força física e do saber.

Na adubação manual ou na polinização do maracujá, a preferência pelas mulheres é justificada pelos empregadores e gerentes pela aptidão "natural". No entanto, acredita-se que a experiência das mulheres na esfera doméstica contribui enormemente para o domínio de atividades que dependem da coordenação motora fina, do manuseio dos pequenos músculos, imprescindível na preparação de alimentos, na costura e no trato com as crianças. Todas essas atividades estão tradicionalmente circunscritas ao domínio doméstico, espaço associado às mulheres.

O funcionamento ainda parcial do Platô não foi suficiente para atrair trabalhadores rurais migrantes, apesar do número significativo de técnicos e agrônomos e empresários originários de outros municípios e regiões do país diferentemente do Vale do São Francisco, onde se formou um verdadeiro contigente de trabalhadores originários de outros municípios que, ali perambulam, de lote em lote. No caso do Platô, trabalhadores locais, residentes em povoados ou sedes municipais próximas, recrutados por redes de interconhecimento que funcionam na seleção de novos trabalhadores, formam a força-detrabalho. Essas redes têm também um papel de controle social, exercido pelos vínculos de parentesco e amizade. Acredita-se que essas redes têm reforçado o recrutamento de homens, seja para a preservação de um padrão cultural, seja pela estratégia de diminuição da pressão sobre as vagas, mas e principalmente, como parte de uma estratégia de reprodução em que compete aos homens a responsabilidade pela manutenção do grupo doméstico.

Nesse sentido, "a compreensão da divisão sexual do trabalho profissional requer a introdução de dimensões explicativas oriundas da esfera extraprofissional, como, por exemplo, a atribuição diferenciada das tarefas domésticas, ou, mais geralmente, as correlações de força e as relações de poder entre os sexos não apenas na empresa, mas também na família e na sociedade" Hirata (1998, p. 15).

\section{Geração de ocupações}

A previsão do número de empregos a serem gerados no Projeto de Irrigação Platô de Neópolis é de 5.600 entre diretos e permanentes (PADR ÃO, 1996). No entanto, até agosto/2002, o número total de empregos era 829, sendo 651 registrados e 178 clandestinos. Esse número de empregos contrapostos aos 4478 ha em operação significa que a média geral é de 5 ha/homem.

Pelo número de empregos gerados até o momento e fazendo uma projeção para o funcionamento total do projeto Platô de Neópolis, dificilmente se atingirá o estipulado. Isso porque nas áreas irrigadas, uma das etapas que mais demanda trabalho é a pós-colheita e, no caso em análise, um terço da área está ocupada com a cultura do coco, que dispensa esse tipo de serviço.

Apesar da desproporcionalidade entre o previsto e o real, a tendência é de predominância do emprego registrado sobre o clandestino, condição oposta ao observado na agricultura chilena, argentina e mexicana (LARA, 1998; GÓMEZ, 1999; BENDINI, 1999). As possíveis explicações para essa contra-tendência é a tentativa de manutenção de um contingente fixo de trabalhadores, que garanta o cumprimento de prazos e a qualidade dos produtos, evitando a rotatividade desses entre o assalariamento, o extrativismo ou o trabalho por conta própria, estratégias de sobrevivência freqüentemente utilizadas nessa região, onde o trabalho assalariado na agricultura é um acontecimento que data dos anos 80 .

A regularização da relação de trabalho, nesse caso, é uma tentativa de "segurar" os trabalhadores pelas

Ciênc. agrotec., Lavras, v. 29, n. 4, p. 899-906, jul./ago., 2005 
vantagens que apresenta, num contexto nacional de intensificação da precarização. Mesmo assim, as entradas e saídas, por iniciativa dos trabalhadores, bem como a falta de assiduidade, são dados que surpreendem e sugerem que a importância do trabalho para eles não é única, da mesma forma que ter um trabalho assalariado não constitui o desejo de todos. Por outro lado, o papel fiscalizador exercido severamente pelo Estado, por meio da Delegacia Regional do Trabalho, tem inibido a utilização do trabalho clandestino com ganhos para os trabalhadores.

\section{CONCLUSÕES}

Na configuração das relações de trabalho no Projeto de Irrigação Platô de Neópolis, um dos aspectos que mais chama a atenção é a relação entre ocupação e gênero, com os homens ocupando a quase totalidade dos postos de trabalho e as mulheres inserindo-se apenas de forma precária e pontual, mesmo que, no discurso dos técnicos e gerentes, haja o reconhecimento do trabalho feminino como o mais adequado para as tarefas mais leves, como adubação e cata às baratas do coqueiro, ambas atividades temporárias. As mulheres são consideradas também mais atenciosas, detalhistas, "obedientes" e limpas, muito embora essas características sejam fundamentais para poucas atividades na agricultura do Platô.

Essas associações também foram constatadas por Cavalcanti et al. (1998) no Vale do São Francisco, onde as mulheres têm atribuições específicas na viticultura, uma das culturas cujos tratos culturais mais exigem trabalho humano.

$\mathrm{Na}$ região do Platô, a preferência pelos trabalhadores homens tem depurado as relações entre as mulheres, que ficam mais seguidamente na esfera doméstica. Ai, elas inserem-se em redes de ajuda mútua e de realização de atividades alternativas (artesanato, pesca, costura) que têm ajudado a conviver com o desemprego e a assegurar ganhos que não são provenientes do assalariamento.

A alocação de papéis sociais, em que compete à mulher as atividades mais leves ou menos especializadas e aos homens as mais pesadas ou especializadas, freqüentemente conduz à naturalização de papéis construídos socialmente, dificultando, assim, a sua contestação, o que poderia levar a uma menor rigidez na mobilidade ocupacional.

Apesar de as mulheres estarem quase excluídas das atividades assalariadas regulares no Platô de Neopolis, essa não é a tendência geral, considerando que elas mesmas ocupam cerca de $40 \%$ dos postos de trabalho em muitos países avançados (ANTUNES, 2000). Isso não significa desconhecer que estejam sujeitas mais freqüentemente à precarização e a diferenças salariais e tipos de atividades que são associadas ao gênero. Ou seja, salários normalmente mais baixos e atividades mais rotineiras predominam entre as mulheres, muito embora os empregadores reconheçam as suas qualificações, o que permite concluir que, na divisão sexual do trabalho no contexto da reestruturação produtiva, pode-se perceber uma exploração ainda mais intensificada no universo feminino.

Essa realidade não é diferente no Platô, onde a organização da força de trabalho revela uma assimetria sexual que corresponde a uma divisão institucional entre as esferas de atividade doméstica e pública. Às mulheres compete administrar a casa, as crianças, ou seja, uma vida construída em torno da reprodução, dos laços afetivos e familiares. Aos homens, compete o dia-a-dia relacionado à coletividade, ao trabalho. Nessa relação doméstico-público as atividades públicas são mais valorizadas do que as domésticas, em decorrência do reconhecimento que têm por estarem ligadas diretamente à geração de valor.

Em conseqüência, o envolvimento nas atividades do Platô é masculino ou feminino segundo o tipo de trabalho, máquinas, turnos de trabalho. Normalmente, o trabalho considerado leve, repetitivo e esporádico é atribuído às mulheres e aqueles que requerem conhecimentos técnicos é atribuído aos homens. Isso não significa que nesse contexto específico não tenha homens também executando trabalhos repetitivos, dada a quase exclusão das mulheres desse universo ocupacional.

Além de todas as discriminações experimentadas pelas mulheres nas novas situações de trabalho, normalmente elas realizam atividades fora e dentro de casa, espaço onde se criam as condições para a reprodução social da família. Mesmo assim, não há como negar que a ampliação do trabalho feminino nas últimas décadas é parte do processo de emancipação parcial das mulheres, tanto em relação à sociedade de classes quanto às inúmeras formas de opressão masculina, que se fundamentam na tradicional divisão social e sexual do trabalho. Mas, segundo Antunes (2000), o capital incorpora o trabalho feminino de modo desigual e diferenciado em sua divisão social e sexual do trabalho. 


\section{REFERÊNCIASBIBLIOGRÁFICAS}

ANTUNES, R. Adeus ao trabalho?: ensaio sobre as metamorfoses e a centralidade no mundo do trabalho. Campinas: Cortez, 1999.280 p.

ANTUNES, R. Os sentidos do trabalho: ensaio sobre a afirmação e a negação do trabalho. São Paulo: Bom Tempo, 2000. 258 p.

BENDINI, M. Entre maçãs e pêras: globalização, competitividade e trabalho. In: CAVALCANTI, J. S. B. (Org.). Globalização, trabalho, meio ambiente: mudanças socioeconômicas em regiões frutícolas para exportação, Recife: EDUFPE, 1999.

CAVALCANTI, J. S. B. Frutas para o mercado global. Estudos Avançados, São Paulo, n. 29, p. 79-93, 1997.

CAVALCANTI, J. S. B.; IRMÃO, J. F. Globalização, integração regional e seus impactos sobre a produção familiar: um estudo sobre os sistemas de produção do Vale São Francisco - NE - Brasil. In: ENCONTRO NACIONAL DO PROJETO DE INTERCÂMBIO DE PESQUISA SOCIAL EM AGRICULTURA, 17., 1994, Porto Alegre. Anais... Porto Alegre: APIPSA, 1994. v. 2, p. 59-72.

CAVALCANTI, J. S. B.; RAMOS, J. V. R.; SILVA, A. C. B. da. O Trabalho feminino na agricultura de exportação: as trabalhadoras na viticultura. In: ALBANO, L.; ABREU, A. R. de P. (Orgs.). Gênero e trabalho na sociologia latinoamericana. São Paulo: ALAST, 1998.

CAVALCANTI, J. S. B. Globalização e processos sociais na fruticultura de exportação do Vale do São Francisco. In:

. Globalização, trabalho, meio ambiente: mudanças socioeconômicas em regiões frutícolas para exportação. Recife: EDUFPE, 1999.
GÓMEZ, S. Exportação de frutas chilenas: reflexões sociológicas sobre uma experiência (madura?). In: CAVALCANTI, J. S. B. (Org.). Globalização, trabalho, meio ambiente: mudanças socioeconômicas em regiões frutícolas para exportação. Recife: EDUFPE, 1999.

HIRATA, H. Reestruturação produtiva, trabalho e relações de gênero. Estudio del Trabajo, [S.I.], v. 4, n. 7, p. 5-27, 1998.

LARA, S. M. Nuevas experiencias productivas y nuevas formas de organización flexible del trabajo en la agricultura mexicana. Cidade do México: Juan Pablos, $1998.350 \mathrm{p}$.

MOTA, D. M. da. O Projeto de irrigação Platô de Neópolis e a geração de empregos 1994/2000: relatório de pesquisa. Aracaju: Embrapa-CPATC, 1998.

MOTA, D. M. da. Trabalho permanente e temporário na fruticultura irrigada nordestina: o Platô de Neópolis, SE. Raízes, São Paulo, v. 20, p. 63-75, 1999.

MOTA, D. M. da. O trabalho temporário no projeto de irrigação Platô de Neópolis, SE. Cadernos de Ciência \& Tecnologia, Brasília, v. 18, p. 113-134, 2001.

PADRÃO, L. N. Levantamento de informações sobre o Projeto Platô de Neópolis. Aracaju: Centro de Assessoria e Serviços aos trabalhadores da terra D. José Brandão de Castro, 1996.34 p.

SILVA, A. G. da. Trabalho e tecnologia na produção de frutas irrigadas no Rio Grande do Norte. In: CAVALCANTI, J. S. B. (Org.). Globalização, trabalho, meio ambiente: mudanças socioeconômicas em regiões frutícolas para exportação. Recife: EDUFPE, 1999.

STOLCKE, V. A família que não é sagrada. In: CORRÊA, M. (Org.). Estudos sobre a família no Brasil. São Paulo: Brasiliense, 1982. 